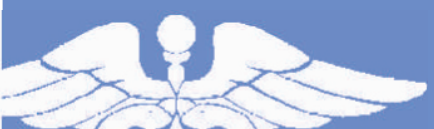

ISSN: 2782-7550 (Print) ISSN: 2782-7542 (Online)
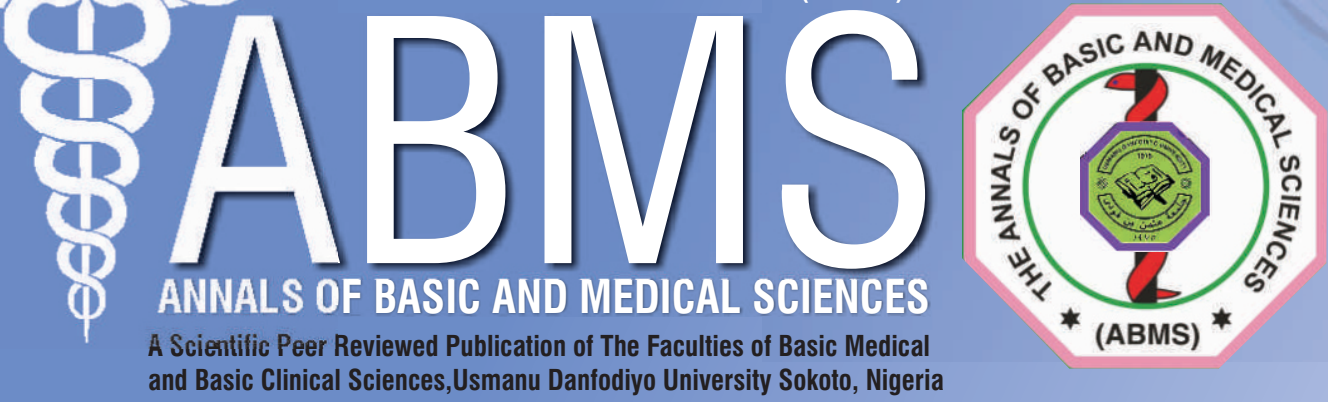

and Basic Clinical Sciences,Usmanu Danfodiyo University Sokoto, Nigeria
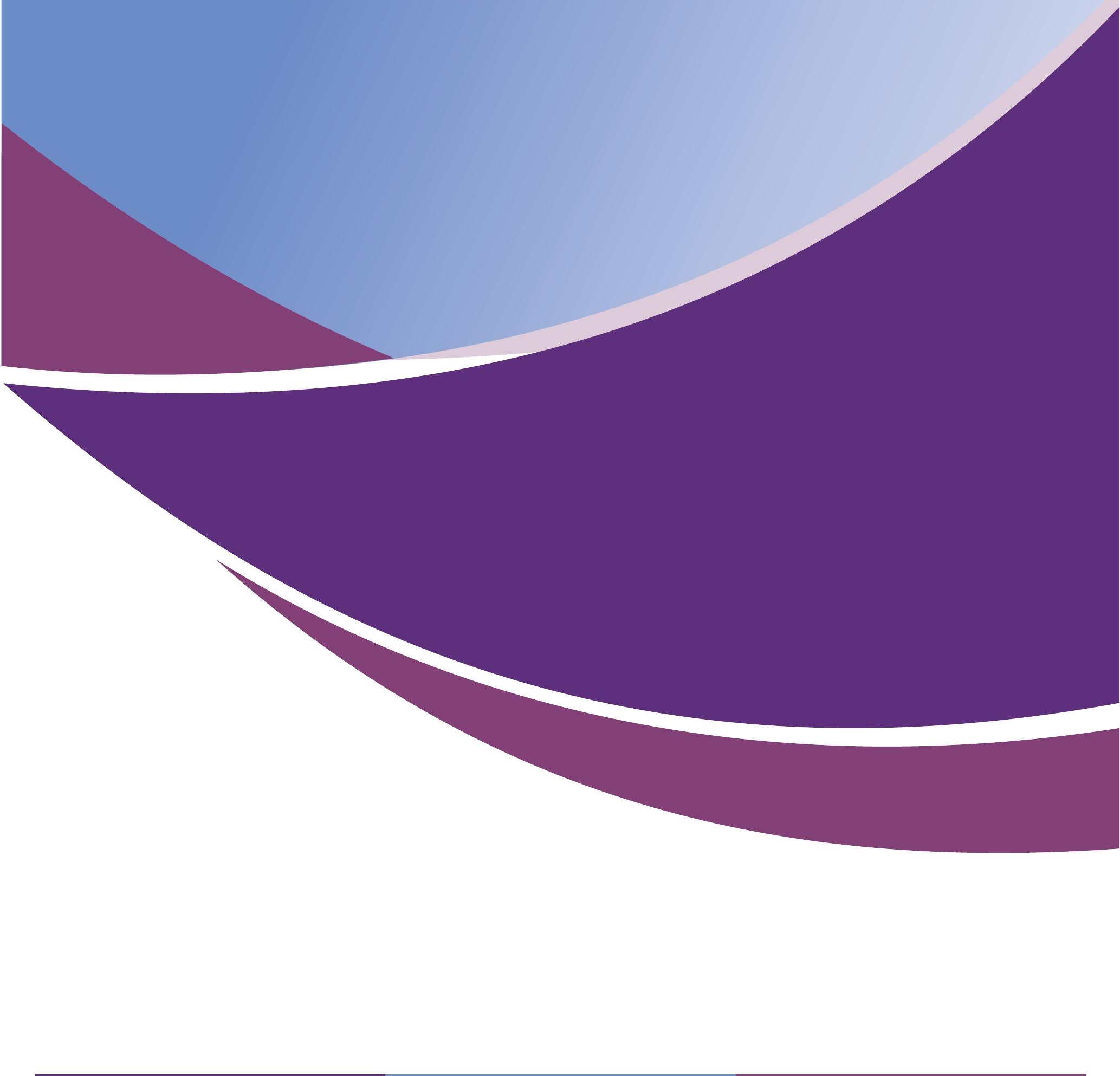

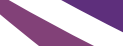
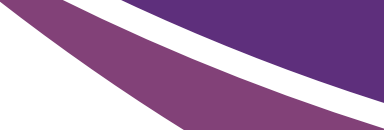


\title{
Emergency Contraceptives: Knowledge, Attitude and Prescription Practice of Primary Healthcare workers in Sokoto Metropolis, Northwest Nigeria.
}

\author{
Mansur O. Raji', Sahiha Wakkala', Ummu Salma Mustapha', Usman Danmalam', \\ Ismail A Raji ${ }^{2}$, Hadija O. Raji ${ }^{3}$, and Ahunna Z. Ezenwoko ${ }^{2}$.
}

\author{
${ }^{1}$ Department of Community Health, Usmanu Danfodiyo University, Sokoto, Nigeria. \\ ${ }^{2}$ Department of Community Medicine, Usmanu Danfodiyo University Teaching Hospital, Sokoto, Nigeria \\ ${ }^{3}$ Department of Obstetrics and Gynaecology, University of Ilorin, Kwara State, Nigeria
}

\begin{abstract}
Background: Emergency contraception refers to methods of contraception that can be used to prevent pregnancy after sexual intercourse. About thirty percent of all pregnancies, and $61 \%$ of all unintended pregnancies, ended in an induced abortion in Nigeria, and many women with unwanted pregnancies decide to end them by abortion. Healthcare providers' knowledge and attitude towards emergency contraception is very important for dissemination of awareness, consumer acceptance and use of contraceptives, as health care workers interact with large numbers of women and are reliable sources of information. This study aimed to assess healthcare workers' emergency contraception knowledge, attitude and prescription practice.
\end{abstract}

Materials and Methods: The study was a cross-sectional study. Healthcare workers providing services in Primary Health care facilities of Sokoto metropolis were studied. Using formula for sample size estimation for crosssectional study, a total of 419 respondents were recruited into the study using systematic sampling technique. The instrument of data collection was a structured interviewer administered questionnaire and data was collected by means of Open Data Kit for android App and analysed using IBM SPSS statistical software package version 23. Univariate and bivariate analysis were conducted; level of significance was set at $5 \%$.

Results: Few (39.9\%) respondents knew that Intra uterine contraceptive devices can be used for emergency contraception, only $15.4 \%$ knew how emergency contraceptives work. Most $(75.4 \%)$ believed that emergency contraceptives should be available only on prescription; and $30.5 \%$ felt that emergency contraceptive pills promote irresponsible behaviour. More than half of the respondents $(56.5 \%)$ had prescribed within the last one month, $48.7 \%$ of them prescribed less than 5 times within the month. Only $27(8.0 \%)$ have ever prescribed emergency contraceptive pills in advance of need.

Conclusion: The study respondents had good knowledge of emergency contraceptives, albeit, with some misconceptions, they also demonstrated good attitude, however, the prescription practice was fair.

Keywords: Primary Health Care Workers, Emergency Contraception, Knowledge, Attitude, prescription

Corresponding author: Mansur Olayinka Raji Department of Community Health Usmanu Danfodiyo University, Sokoto, Nigeria. E mail: mansurraji@gmail.com Tel No: +234803 7177017

\section{Introduction}

둘 mergency contraception (EC) refers to methods of contraception that can be used to prevent pregnancy after unprotected sexual intercourse (1). Emergency Contraceptive Pills (ECPs) are pills used for preventing pregnancy after unprotected intercourse, they are sometimes referred to as "the morning after pill" or "postcoital oral contraceptives (2)." Emergency contraceptive pills recommended by WHO are ulipristal acetate, levonorgestrel, or combined oral contraceptives (COCs) consisting of ethinyl estradiol plus levonorgestrel. 'The effectiveness of emergency contraception is limited by timing of administration and can prevent up to over $95 \%$ of pregnancies when taken within 5 days after intercourse (3). The need for EC may arise when following sexual intercourse the following occurs; no contraceptive method was used, contraceptive failure occurs or incorrect use of contraceptives, such as incorrect use of condom or breakage, three or more consecutive missed combined oral contraceptive pills (OCP), delay more than two weeks for injectable method, failed withdrawal method, intra uterine device (IUD) expulsion and case of sexual assault when woman is not protected by contraception (4). 
Despite the availability of highly effective methods of contraception, many pregnancies are mistimed or unintended. These pregnancies may carry a high risk of morbidity and mortality, particularly in settings where safe abortion is not accessible or where quality obstetric services are not available for those women continuing a pregnancy to term. Many of these unintended pregnancies can be avoided using emergency contraception (2).

Between 2015 and 2019, on average, 73.3 million induced (safe and unsafe) abortions occurred worldwide each year (3). About 3 out of 10 (29\%) of all pregnancies, and 6 out of $10(61 \%)$ of all unintended pregnancies, ended in an induced abortion (3). Sub-Saharan Africa has the highest pregnancy rate of (218 per 1,000 women per year). The region has the highest unintended pregnancy rate $(91$ per 1,000$)$. Among women who become pregnant without intending to be, an estimated $37 \%$ terminate the pregnancy (5). From 1990-2019, the share of unintended pregnancies resolved through abortion increased by $26 \%$ in Middle Africa, by $44 \%$ in both Eastern and Western Africa and by $72 \%$ in Southern Africa as of 2019 (5). Some 6.2 million unsafe abortions occur in the region per year and the region has the highest rate of abortion-related deaths in the world, at 185 maternal deaths per 100,000 abortions (5).

In Nigeria, unintended sexual intercourse is the primary cause of unwanted pregnancies, and many women with unwanted pregnancies decide to end them by abortion (6). Since abortion is illegal in Nigeria (unless medically recommended to save a mother's life), many abortions are carried out clandestinely, and often in an unsafe environment (6). The consequences of these clandestine abortions are grave and can be life-threatening, often leading to maternal death (6).

The Percent distribution of currently married and sexually active unmarried women age $15-49$ by contraceptive method currently using emergency contraceptive in urban setting in Nigeria is low i.e. only $0.3 \%$ (7).

Although EC is widely available in many countries, making it available is not enough in itself to prevent unwanted pregnancies and abortions that result from unprotected intercourse. People need to know that it exists; thus the communication component of an introduction strategy for emergency contraception is a key determinant of success (8). EC use has been marred with controversies and misperceptions in some countries, especially concerning its mode of action, impact on behaviour and safety (9) while it has been welcomed in some countries as just another contraceptive option and part of a broader reproductive health agenda. In others, EC has been met by claims that it is an abortifacient, a sign of the population's moral degeneracy, or a tool for abusing children (9). In order to eliminate these misconceptions, healthcare providers' knowledge and attitude towards emergency contraception therefore become key to the dissemination of awareness, consumer acceptance and use of contraceptives for their all-time benefits (10) since they interact with large numbers of women and are reliable sources of information. They have influence on women's contraceptive behaviour and their knowledge and attitudes about EC can impede or promote women's use (4).

Furthermore, studies have shown that women who are counselled by their health care workers about emergency contraception were 11 times more likely to use emergency contraception in the following 12 months (11). Health care workers' knowledge about emergency contraception and attitude towards emergency contraception therefore become key to the dissemination of awareness, consumer acceptance and use of contraceptives for their all-time benefits in developing countries (8) Healthcare professionals have a responsibility to counsel and offer their patients knowledge on all forms of contraception, including EC (9). Studies have shown that Lack of knowledge and misperceptions about EC also exists among healthcare workers, therefore hindering the dissemination of knowledge to patients (9). Many healthcare professionals have poor knowledge and poor attitude towards emergency contraception especially the general practitioners and those who have worked for more than ten years. The practice of EC is generally poor among the respondents and this may add to unmet needs for contraception (12). This study aimed to assess health care workers' emergency contraception knowledge, attitude and prescription practice.

\section{Materials and Methods}

The study was conducted in Sokoto metropolis. Sokoto metropolis consists of Sokoto North, Sokoto South, Parts of Dange/Shuni and Wammako LGAs. The state has a total of 574 primary health facilities (13), however, the Sokoto Metropolis) has a total of 52 primary health facilities. These facilities are mainly manned by nurses, community health officers $(\mathrm{CHO})$ and community health extension workers (CHEWS), however a few have doctors manning them.

The study was cross-sectional and analytical in nature. The study population comprised of Primary Health Care (PHC) workers (Nurses, $\mathrm{CHO}$ and $\mathrm{CHEWS}$ ) working in the selected facilities. Only study participants who had worked in these facilities for minimum of 6 months were included in the study. Sample size was estimated using formula for sample size estimation for cross-sectional studies, where P (33.2\%) (14) was the Prevalence of knowledge of emergency contraception among $\mathrm{PHC}$ workers, allowing for a response rate of $80 \%$, a total of 419 respondents were enrolled into the study using systematic sampling technique.

The instrument of data collection was by means of structured interviewer administered questionnaire adapted from previous studies. The questionnaire had 4 sections which sought for information on respondents sociodemographic characteristics, their knowledge, attitude and prescription practices of emergency contraception. The questionnaire was pretested among $41 \mathrm{PHC}$ workers 
at a Primary Health Care facility in Sokoto that was not part of the study site. Data was collected by trained research assistants using open data kit (ODK) installed into their android smart phones and tablets. At the end of data collection, completed forms were extracted from the ODK server in excel format and exported into IBM SPSS version 23 software for analysis.

Respondents knowledge of emergency contraceptives was assessed using 6 item questions. One mark was awarded for every question answered correctly, zero marks was given for every questioned answered wrongly or not answered at all. Knowledge score was obtained by summing up the scores divided by 6 and converting to percentages. Scores $<50 \%$ and $\geq 50 \%$ were regarded as poor and good knowledge respectively. Univariate variables were summarised using frequencies and percentages for qualitative data and means and standard deviation for quantitative variables. Chi square test statistic was used to test for association between socio-demographic characteristics of respondents and their knowledge, attitude and prescription practices of emergency contraception.

Ethical clearance was obtained from the Ethics and Review Committee of the Sokoto State Ministry of Health, Nigeria. Permission was sought from the Heads of the different PHCs. Informed verbal and written consent was sought from each study participant before enrolment into the study. They were intimated about the research protocol, objectives of the research, any potential risks and benefits associated with involvement in the research. They were assured of confidentiality of study findings and their freewill to opt out of the study voluntarily at any stage of the study.

\section{Results}

More than two-thirds of the study respondents 236 $(69.8 \%)$ were less than 40 years and slightly above half, [187 (55.3\%)] were females. Almost one-third, [104 (30.8\%] of the respondents have more than 10 years since basic qualification and more than half, 151 (55.7\%) have never had any training on emergency contraception (Table 1)

Majority, 270 (79.9\%) of the respondents knew that emergency contraception is legal in Nigeria. Many, 218 (64.5\%) and majority, 291 (86.1\%) knew that combined oral contraceptive pills and Postinor respectively were used for emergency contraception. Only 39.9\% knew that IUCD can be used for emergency contraception. A great majority, $310(91.7 \%)$ and 285 (84.3\%) knew that a woman who has been raped and sexual intercourse following a condom breakage, respectively can be given emergency contraception. More than two-third, 219 (64.8\%) knew that emergency contraception should be given within 5 days of unprotected intercourse, only $15.4 \%$ of respondents knew how emergency contraceptives work (Table 2).

Two hundred and fifty-five respondents (75.4\%) believed that emergency contraceptives should be available only on prescription; and 103 (30.5\%) felt that emergency contraceptive pills promote irresponsible behaviour (Table 3).

Majority, 316 (93.5\%) of the respondents have prescribed emergency contraception at least once and 191 (56.5\%) have prescribed within the last one month. Among those who prescribed within one month, 93 $(48.7 \%)$ prescribed less than 5 times within the month. Only $27(8.0 \%)$ have ever prescribed emergency contraceptive pills in advance of need (Table 4).

One hundred and one (42.8\%) of those below 40 years had good knowledge compared to 45 (44.1\%) among those who are greater than 40 years and the difference was not statistically significant, $p=0.822$. A higher proportion, 49 (47\%) of those with $\geq 10$ years of work experience had good knowledge compared to those with less than 10 years of work experience; and those $\geq 10$ years of work experience are 1.26 times more likely to have good knowledge, however, this finding is not statistically significant. A higher proportion of those who had training, $95(50.8 \%)$ had good knowledge compared to 51 (33.85\%) of those who had not training. Those who did not have any training were less likely to have good knowledge, 0.49 (95\% Cl= 0.32 - 0.77), p = 0.002 (Table 5).

Table 1: Sociodemographic profile of respondents

\begin{tabular}{|c|c|c|}
\hline Varible & Frequencies & Percentages \\
\hline \multicolumn{3}{|l|}{ Age group } \\
\hline$<40 y r s$ & 236 & 69.8 \\
\hline$\geq 40$ yrs & 102 & 30.2 \\
\hline \multicolumn{3}{|l|}{ Gender } \\
\hline Male & 151 & 44.7 \\
\hline Female & 187 & 55.3 \\
\hline \multicolumn{3}{|l|}{ Religion } \\
\hline Islam & 305 & 90.2 \\
\hline Christianity & 33 & 9.8 \\
\hline \multicolumn{3}{|l|}{ Ethnic group } \\
\hline Hausa & 199 & 58.9 \\
\hline Fulani & 62 & 18.3 \\
\hline Yoruba & 48 & 14.2 \\
\hline $\operatorname{lgbo}$ & 25 & 7.4 \\
\hline Others & 4 & 1.2 \\
\hline \multicolumn{3}{|c|}{ Years of qualification } \\
\hline$<10$ & 234 & 69.2 \\
\hline$\geq 10$ & 104 & 30.8 \\
\hline \multicolumn{3}{|l|}{ Work cadre } \\
\hline $\mathrm{CHO}$ & 58 & 17.2 \\
\hline Midwife & 54 & 16.0 \\
\hline Nurse & 75 & 22.2 \\
\hline Chew & 151 & 44.7 \\
\hline \multicolumn{3}{|c|}{$\begin{array}{l}\text { Had training on } \\
\text { emergency contraceptio }\end{array}$} \\
\hline Yes & 187 & 55.3 \\
\hline No & 151 & 44.7 \\
\hline
\end{tabular}

\section{Discussion}

Our study was able to demonstrate some level of general knowledge of EC among health care workers, however detailed knowledge of EC was lacking around crucial issues such as the different types, timing, mechanism 
Table 2: Knowledge of Emergency contraception

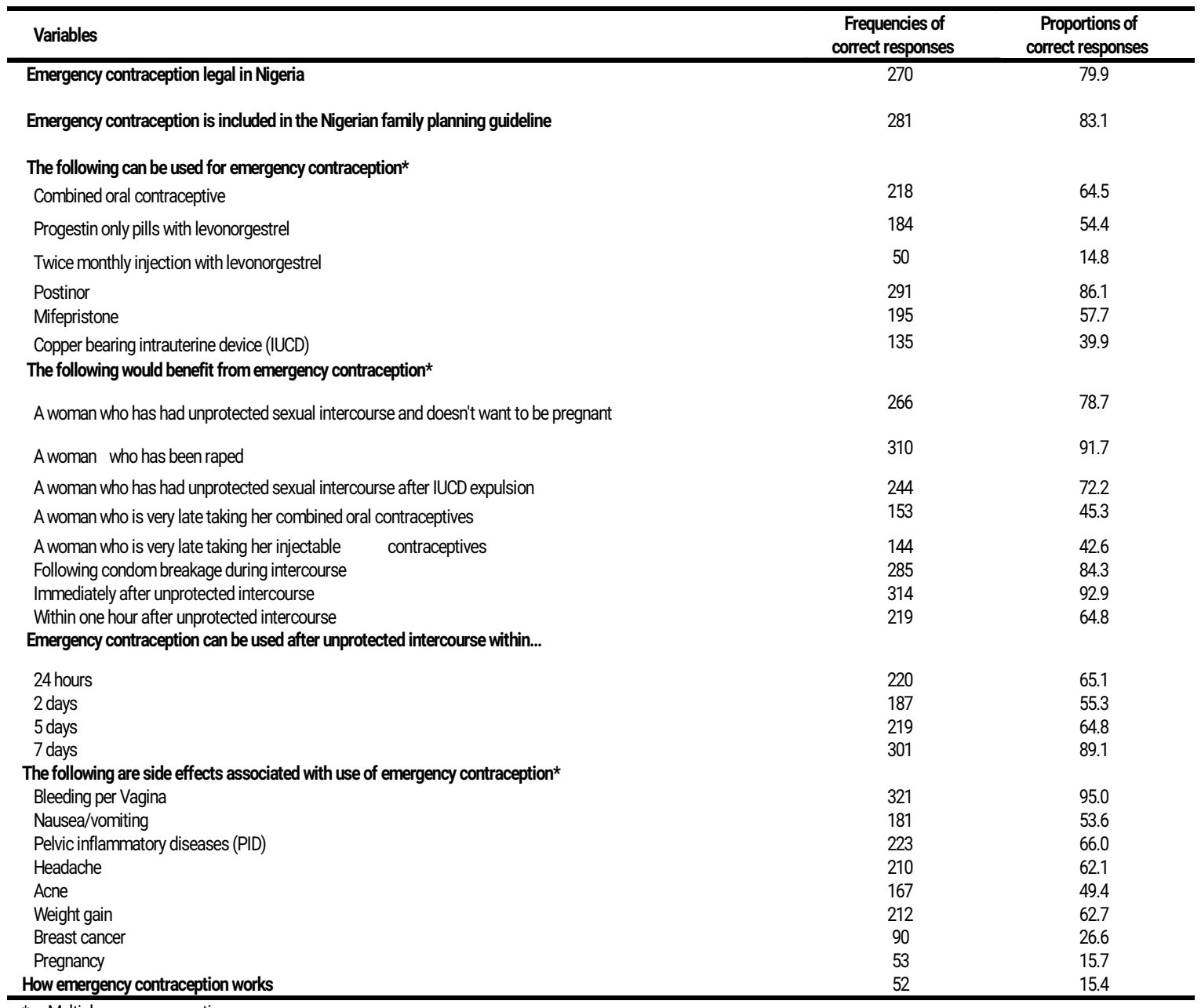

Table 3: Attitude of respondents towards emergency contraception

\begin{tabular}{|c|c|c|c|}
\hline \multirow{2}{*}{ Attitude } & \multirow{2}{*}{$\begin{array}{l}\text { Agree } \\
\text { Frequency (\%) }\end{array}$} & \multirow{2}{*}{$\begin{array}{l}\text { Disagree } \\
\text { Frequency (\%) }\end{array}$} & \multirow{2}{*}{$\begin{array}{l}\text { Not certain } \\
\text { Frequency (\%) }\end{array}$} \\
\hline & & & \\
\hline $\begin{array}{l}\text { Emergency contraceptives } \\
\text { should not be available at all }\end{array}$ & $25(7.4)$ & $292(86.4)$ & $21(6.2)$ \\
\hline $\begin{array}{l}\text { Emergency contraceptives } \\
\text { should be available only on } \\
\text { prescription }\end{array}$ & $255(75.4)$ & $58(17.2)$ & $25(7.4)$ \\
\hline $\begin{array}{l}\text { Emergency contraceptive pills } \\
\text { should be accessed over the } \\
\text { counter }\end{array}$ & $222(65.7)$ & $57(16.9)$ & $59(17.5)$ \\
\hline $\begin{array}{l}\text { Emergency contraceptives } \\
\text { promote irresponsible } \\
\text { behaviour }\end{array}$ & $103(30.5)$ & $174(51.5)$ & $61(18.0)$ \\
\hline $\begin{array}{l}\text { Emergency contraceptives } \\
\text { should be provided to women } \\
\text { of reproductive age in } \\
\text { advance of need }\end{array}$ & $272(80.5)$ & $25(7.4)$ & 41 (12.1) \\
\hline
\end{tabular}

of action of EC. Some of our respondents also demonstrated inaccurate knowledge about the legal status of EC in Nigeria.

Many of the respondents knew that combined oral contraceptive pills as well as postinor can be used for emergency contraception. About a third knew that IUCD can be used for emergency contraception. This result is in line with a previous study conducted in Nigeria (8), which reported that $25.3 \%$ knew IUCD can be used for emergency contraception, but contrast with a another study among health care workers which reported that half of the respondents knew that IUCD can be used for emergency contraception (15).

A great majority, $310(91.7 \%)$ and $285(84.3 \%)$ knew that a woman who has been raped and a woman who had condom breakage following a condom breakage, respectively can be given emergency contraception. This level of knowledge may mean that majority of women who need EC due to rape or condom breakage following intercourse may have EC recommended to them if they present to primary health care centres. 
Table 4: Practice of emergency contraception prescription among respondents

Variables $\quad$ Frequency Percent

\begin{tabular}{|c|c|c|}
\hline \multicolumn{3}{|l|}{ Ever prescribed emergency contraception } \\
\hline Yes & 316 & 93.5 \\
\hline No & 22 & 6.5 \\
\hline \multicolumn{3}{|l|}{ Prescribed emergency contraception within the last one month } \\
\hline Yes & 191 & 56.5 \\
\hline No & 147 & 43.5 \\
\hline \multicolumn{3}{|l|}{ How many times prescribed in the last one month $(n=191)$} \\
\hline$\geq 5$ & 98 & 51.3 \\
\hline$<5$ & 93 & 48.7 \\
\hline \multicolumn{3}{|l|}{ Prescribed emergency contraception within the last 1 year? } \\
\hline Yes & 312 & 92.3 \\
\hline No & 26 & 7.7 \\
\hline \multicolumn{3}{|l|}{$\begin{array}{l}\text { Methods of emergency contraceptive ever prescribed for } \\
\text { women of reproductive age* }\end{array}$} \\
\hline Combined oral contraceptive & 170 & 50.3 \\
\hline Progestin only pills with levonorgestrel & 229 & 67.8 \\
\hline Methods/twice monthly injection with levonorgestrel & 271 & 80.2 \\
\hline Postinor & 239 & 70.7 \\
\hline Mifepristone & 148 & 43.8 \\
\hline Copper bearing intrauterine device & 53 & 15.7 \\
\hline \multicolumn{3}{|l|}{$\begin{array}{l}\text { Have you ever provided women of reproductive age with } \\
\text { emergency contraceptive in advance of need? }\end{array}$} \\
\hline Yes & 27 & 8.0 \\
\hline No & 311 & 92.0 \\
\hline
\end{tabular}

* Multiple responses

Table 5: Relationship between knowledge and sociodemographic factors

\begin{tabular}{|c|c|c|c|c|c|}
\hline \multirow{2}{*}{ Variables } & \multicolumn{2}{|l|}{ Knowledge } & \multirow{2}{*}{$\begin{array}{l}\text { Chi } \\
\text { square } \\
\text { p value }\end{array}$} & \multirow{2}{*}{ OR } & \multirow{2}{*}{$\mathrm{Cl}(95 \% \mathrm{Cl})$} \\
\hline & Poor & Good & & & \\
\hline \multicolumn{6}{|l|}{ Age group (Years) } \\
\hline $\begin{array}{l}<40 \\
\geq 40\end{array}$ & $\begin{array}{l}135(57.2) \\
57(55.9)\end{array}$ & $\begin{array}{l}101(42.8) \\
45(44.1)\end{array}$ & $\begin{array}{l}0.051 \\
0.822\end{array}$ & 1.1 & $1.06(0.66-1.69)$ \\
\hline $\begin{array}{l}\text { Gender } \\
\text { male } \\
\text { female }\end{array}$ & $\begin{array}{l}79(52.3) \\
113(60.4)\end{array}$ & $\begin{array}{l}72(47.7) \\
74(39.6)\end{array}$ & $\begin{array}{l}2.239 \\
0.135\end{array}$ & 0.72 & $0.72(0.47-1.11)$ \\
\hline $\begin{array}{l}\text { Religion } \\
\text { Islam } \\
\text { Christianity }\end{array}$ & $\begin{array}{l}168(55.1) \\
24(72.7)\end{array}$ & $\begin{array}{l}137(44.9) \\
9(27.3)\end{array}$ & $\begin{array}{l}3.779 \\
0.052\end{array}$ & 0.46 & $0.46(0.21-1.02)$ \\
\hline $\begin{array}{l}\text { Ethnic group } \\
\text { Hausa/Fulani } \\
\text { Yoruba/lbo/others }\end{array}$ & $\begin{array}{l}145(55.6) \\
47(61.0)\end{array}$ & $\begin{array}{l}116(44.4) \\
30(39.0)\end{array}$ & $\begin{array}{l}0.729 \\
0.393\end{array}$ & 0.79 & $0.80(0.47-1.34)$ \\
\hline $\begin{array}{l}\text { CHO/CHEW } \\
\text { Nurse/Midwife }\end{array}$ & $\begin{array}{l}112(53.6) \\
80(62.0)\end{array}$ & $\begin{array}{l}97(46.4) \\
49(38.0)\end{array}$ & $\begin{array}{l}2.309 \\
0.129\end{array}$ & 0.71 & $0.71(0.45-1.11)$ \\
\hline $\begin{array}{l}\text { Years of qualification } \\
\quad<10 \\
\quad \geq 10\end{array}$ & $\begin{array}{l}137(58.5) \\
55(52.9)\end{array}$ & $\begin{array}{l}97(41.5) \\
49(47.1)\end{array}$ & $\begin{array}{l}0.941 \\
0.332\end{array}$ & 1.26 & $1.26(0.79-2.00)$ \\
\hline \multicolumn{6}{|l|}{$\begin{array}{l}\text { Had training on } \\
\text { emergency contraception }\end{array}$} \\
\hline $\begin{array}{l}\text { Yes } \\
\text { No }\end{array}$ & $\begin{array}{l}92(49.2) \\
100(66.2)\end{array}$ & $\begin{array}{l}95(50.8) \\
51(33.8)\end{array}$ & $\begin{array}{l}9.871 \\
0.002\end{array}$ & 0.49 & $0.49(0.32-0.77)$ \\
\hline
\end{tabular}

Less than two-third of our respondents knew that emergency contraception should be given within 5 days of unprotected intercourse. Another study conducted among physicians in Nigeria reported that $7.6 \%$ knew that emergency contraception may be used up to 5 days after unprotected sexual intercourse (8). Health care workers not knowing the ideal time to provide emergency contraception to clients means that some clients may miss out on using emergency contraception when they need it the most.

Less than a fifth of our respondents knew how emergency contraceptives work. This result is similar to finding from previous studies which reported that few health workers could explain the mechanism of action of emergency contraception $(15,16)$. Although several possible mechanism of action have been postulated, research shows that emergency contraception acts by preventing pregnancy and cannot interrupt an established pregnancy (17). The method's ability to inhibit or delay ovulation has been demonstrated in clinical trials and is an important mechanism of action if emergency contraception is used during the first half of the menstrual cycle before ovulation has occurred (17). Some clinical studies suggest that emergency contraception may make the endometrium less receptive to the implantation of a fertilized egg, although some other studies have not found any effect on the endometrium (17). In addition, emergency contraception may prevent pregnancy by interfering with corpus luteum function; thickening the cervical mucus; altering the tubal transport of sperm, egg or embryo; or directly inhibiting fertilization (17). Having accurate emergency contraception related knowledge is thus invaluable for health care workers to feel comfortable in providing adequate and correct counselling as well as prescribing emergency contraception to clients with ease (15). Overall, our study findings contrasted with a study conducted in Ismailia Governorate, Egypt which reported general lack of knowledge of emergency contraception among health care providers (18).

Three quarters of the study respondents believed that emergency contraceptives should be available only on 
prescription. Availability of emergency contraception only on prescription would further make its access more difficult. Previous studies reported that less than half of the respondents believed that emergency contraception should be available over the counter $(8,16)$.

Level of prescription of emergency contraception among our study respondents was far from encouraging. However, emergency contraception is available in Nigeria without prescription, this may account for low demand for it at our study centres. Studies that evaluate the level of knowledge of emergency contraceptives among patent medicine vendors could greatly enhance awareness and access towards emergency contraceptives. A previous study reported that $18.4 \%$ of study respondents had ever prescribed emergency contraception (15). Another study reported that only 27 (8.0\%) have ever prescribed emergency contraceptive pills in advance of need. Health care workers should be encouraged to provide information on emergency contraception to women of reproductive age at every contact, they should also be encouraged to prescribe them in advance of need.

A higher proportion of respondents with $\geq 10$ years of work experience had good knowledge compared to those with less than 10 years of work experience and those with $\geq 10$ years of work experience were 1.26 times more likely to have good knowledge. Also, a higher proportion of respondents who had been trained on emergency contraceptives had good knowledge compared to those who had not been trained. This is not surprising as training on emergency contraception is usually aimed to improve knowledge, promote positive attitude and eventually increase prescription practice and access to emergency contraception.

\section{Conclusion}

The study respondents had good knowledge of emergency contraceptives, albeit, with some misconceptions, they also demonstrated good attitude, however, there was low prescription practice.

Given the general positive attitude of the study respondents regarding emergency contraception, training health care providers regarding when to initiate treatment, contraindications, and mode of action may be a relatively simple way to increase prescribing, resulting in increased utilization of emergency contraception.

\section{References}

1. World Health Organization. Emergency contraception. 2018. Available from: http://www.who.int/mediacentre/factsheets/fs244/en/.

2. International Consortium for Emergency Contraception. Introduction 2018 Available from: https://www.cecinfo.org/wp-content/uploads/2018/12/ ICEC-guides_FINAL.pdf.

3. WHO. Preventing unsafe abortion 2020 [Available from: https://www.who. int/news-room/fact-sheets/detail/preventing-unsafe-abortion.

4. Najafi-Sharjabad F, Hajivandi A, Rayani M. Knowledge, attitude, and practice about Emergency Contraception among health staff in Bushehr state, south of Iran. Global Journal of Health Science. 2013; 6(1): 52-60.

5. Institute G. Abortion in Sub-Saharan Africa fact sheet 2020 [Available from: https://www.guttmacher.org/fact-sheet/abortion-subsaharan-africa.

6. Lamina MA. Prevalence of Abortion and Contraceptive Practice among Women Seeking Repeat Induced Abortion in Western Nigeria. Journal of Pregnancy. 2015; 2015: 486203.

7. NPC, ICF. Nigeria demographic and health survey 2018. Nigeria: National Population Commission; 2019.

8. Harrison A. Knowledge and attitude towards emergency contraception among medical doctors in Delta State. African Journal of Medical and Health Sciences 2014; 13(1).

9. Sibanda E, Titus M. Knowledge, attitudes and practices of health professionals in public health institutions on emergency contraception in Pieter maritzburg, KwaZulu-Natal Province, South Africa. South African Journal of Obstetrics and Gynaecology. 2017; 23(1): 7-11.

10. Harrison AO. Knowledge and attitude towards emergency contraception among medical doctors in Delta State. African Journal of Medical and Health Sciences. 2014; 13(1): 39.

11. Langston A. Emergency contraception: Update and review. Semin Reprod Med. 2010; 28: 95-102.

12. Farinloye EO, Adeleke NA, Omisore GA, Adebimpe WO. Knowledge, Attitudes and Practice of Contraception among Medical Doctors Attending a Continuing Medical Education Programme in Osogbo, South-Western Nigeria Tropical Journal of Obstetrics and Gynaecology. 2016; 33(1): 91- 8.

13. Sani UM, Oche MO, Raji MO, Ango UM, Jiya NM. Knowledge, Attitude and Reporting Practices on Adverse Events Following Immunization among Routine Immunization Service Providers in Health Facilities of Sokoto State, Nigeria. International Journal of Tropical Disease \& Health. 2019; 2: 1-14.

14. Aodh N, Al-Bargawi M, Al-Otaibi T, Kofi MA. Level of Awareness about Emergency Contraception among Primary Health Care Centers Physicians in Prince Sultan Military Medical City, Riyadh, Saudi Arabia. ARCH Women Health Care. 2019; 2(4): 1-9.

15. Lersbuasin P, Santibenchakul S, Jaisamrarn U. Knowledge, Attitude and Practice regarding Emergency Contraceptive Pills among Health Care Providers. Thai Journal of Obstetrics and Gynaecology. 2015;23:34-43.

16. Chung-Park M. Emergency contraception Knowledge, attitude, practices and barriers among providers at a military treatment facility. Military Medicine. 2008; 173(3): 305-12.

17. Galvão L, Díaz J, Díaz M, Osis M, Clark S, Ellertson C. Emergency Contra ception: Knowledge, Attitudes and Practices Among Brazilian ObstetricianGynecologists. International Family Planning Perspectives. 1999; 25(4): 168-71.

18. Ibrahim Z, Ahmed M, Shaaban M. Knowledge, attitude and practice of emergency contraception among health care providers in Ismailia, Egypt. Middle East Fertility Society Journal 2013; 18: 246-52. 